\title{
POLÍTICAS PÚBLICAS EDUCACIONAIS E AVALIAÇÃO DO ENSINO NOS ESTADOS DA REGIÃO SUL DO BRASIL: UMA ANÁLISE A PARTIR DO PRINCÍPIO FEDERATIVO
}

Michel Alisson da Silva Pedro Henrique Cardoso Hilário

\section{INTRODUÇÃO}

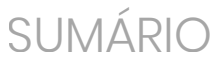

O presente artigo científico tem como propósito caracterizar o princípio federativo no ordenamento jurídico brasileiro à luz da Constituição Federal de 1988. A partir disso, busca-se compreender o federalismo a partir do seu aspecto jus-filosófico, histórico e social do modelo clássico estadunidense; identificar o processo de implantação do princípio federativo no Brasil e seu desenvolvimento até a Constituição Federal de 1988; e analisar as políticas educacionais brasileiras à luz do princípio federativo. Este trabalho apresenta-se de natureza aplicada e tem como método adotado o indutivo. Quanto aos procedimentos metodológicos, em primeiro lugar, foi realizada a revisão bibliográfica das origens do federalismo e de sua implantação no País. Em segundo momento foi realizado um recorte sobre as políticas educacionais analisadas sob a ótica do princípio federativo. $\mathrm{O}$ artigo está dividido em quatro tópicos, a saber: formas de Estado e o surgimento do federalismo, o Estado de bem-estar social brasileiro, o direito à educação como um direito social e políticas públicas educacionais como forma de aplicação dos dispositivos constitucionais.

No decorrer do desenvolvimento deste artigo serão apresentadas as formas existentes de Estado, analisando-se de forma mais detalhada a criação e as características do Estado federal. O Brasil, enquanto uma República Federativa, organizou sua estrutura interna com a distribuição de competências privativas e concorrentes. À União e aos Estados-membros foi atribuída a competência concorrente sobre a educação superior, 
cabendo a primeira a competência privativa de legislar especificamente sobre as diretrizes e bases da educação nacional. Será abordada, também, a importância do Estado de bem-estar social para que haja garantia de direitos sociais à população. Quanto aos direitos sociais, a educação terá enfoque principal, abordando-se, depois, os indicadores educacionais que visam à melhoria do sistema de educação no Brasil.

O estado de bem-estar social surge como uma garantia social com o intuito de fornecer alguns direitos essenciais, como renda, alimentação, saúde a todos os cidadãos. Dentre os direitos assegurados à população, está o direito social fundamental à educação, assegurado no artigo 60 da Constituição Federal de 1988. Para garantir que esse direito social seja aplicado à população, necessárias são as políticas públicas em educação, que visam à melhoria do sistema educacional no País.

\section{FORMAS DE ESTADO E O SURGIMENTO DO FEDERALISMO}

Para entender o Federalismo é necessário, antes de tudo, entender o conceito de Estado. Kelsen (1992, p. 183), pontua que:

Devido à variedade de objetos que o termo normalmente denota, definir "Estado" torna-se difícil. Às vezes, a palavra é usada em um sentido bem amplo, para indicar a "sociedade" como tal, ou alguma forma especial de sociedade. Mas a palavra também é com frequência usada com um sentido bem mais restrito, para indicar um órgão particular da sociedade - por exemplo, o governo, ou os sujeitos do governo, uma "nação", ou o território que eles habitam.

Visando a afastar qualquer confusão entre definição de Estado e sociedade, Dallari (2011, p. 30) afirma que "[...] a sociedade é resultante de uma necessidade natural do homem, sem excluir a participação da consciência e da vontade humanas". Fala também que o contratualismo possui grande influência na formação da sociedade e na ideia contemporânea de democracia. 
Já sobre o Estado, Dallari (2011, p. 59) o conceitua como "[...] situação permanente de convivência e ligada à sociedade política.", e informa que esse conceito aparece pela primeira vez na obra "O Príncipe", de 1513, escrita por Nicolau Maquiavel. Apesar de esta denominação só emergir no século XVI, a maioria dos estudiosos dizem que, antes disso, o Estado já existia, porém, com nomes diferentes. Então, "[...] todas as sociedades políticas que, com autoridade superior, fixaram as regras de convivência de seus membros." são consideradas como Estado.

As "formas estatais pré-modernas" são identificadas por Streck e Morais (2000, p. 20) como: 1) Estado Antigo, que é “[...] uma forma estatal definida entre as antigas civilizações do Oriente ou do Mediterrâneo, onde a família, a religião, o Estado e a organização econômica formavam um conjunto confuso, sem diferenciação aparente"; 2) Estado Grego, que possuía as cidades-Estado (polis), e tinha como objetivo a autossuficiência, além de possuir uma elite política com grande participação nas deliberações do Estado e 3) Estado Romano, que tinha uma "base familiar de organização" e "a noção de povo era restrita, compreendendo apenas faixa estreita da população".

Os autores classificam, ainda, o Estado Medieval como sendo a principal forma de Estado pré-moderna. Para Streck e Morais (2000, p. 2021), o cristianismo, as invasões bárbaras e o feudalismo caracterizam esse período, que foi marcado também por permanente instabilidade política, econômica e social, conflito entre poder espiritual e poder temporal bem como a fragmentação do poder.

Depois do período medieval, surge o chamado Estado Moderno. Conforme Bobbio (2001, p. 67), o nome Estado é "[...] um novo nome para uma realidade nova: a realidade do Estado precisamente moderno, a ser considerado como uma forma de ordenamento tão diverso dos ordenamentos precedentes". Por esse motivo, deve ser denominado de forma diversa das anteriores.

O Estado Moderno, então, deixa de ter as características das formas estatais pré-modernas e passa a derivar da "[...] institucionalização do Poder, sendo que suas condições são o território, a nação, mais potência e autoridade. Esses elementos dão origem à ideia de Estado." (STRECK; MORAIS, 2000, p. 26-27). Essa nova concepção de Estado pode 
ser organizada, basicamente, em duas formas: a forma federada e a forma unitária. Para Streck e Morais (2000, p. 147), a Federação surge apenas a partir do século XVIII, em 1787, quando os Estados Unidos dão origem ao Estado Federado, com a transformação de Confederação em Federação. Sobre o surgimento do federalismo na nação norte-americana, pontua-se que:

[...] o ponto de maior distinção entre o novo sistema para os Estados Unidos e o existente na Grécia, na Itália medieval, na Suiça, na Alemanha ou na Holanda, é que, antes de 1787, o governo central nas federações ou, mais propriamente, nas confederações, não passava de um agente dos Estados. Em nenhum caso ele teve uma existência própria independente, nem o poder para regulamentar os negócios dos cidadãos, criar ou arrecadar impostos dos indivíduos. Não há exemplo de existência de um sistema independente de cortes de justiça ou uma assembleia legislativa eleita pelo povo de toda a confederação. A Constituição de 1787 tem uma antiga ascendência, mas adota um tipo novo de governo federal. (WRIGHT, 1984, p. 49).

Kelsen (1992, p. 309) afirma que "[...] apenas o grau de descentralização diferencia um Estado unitário dividido em províncias autônomas de um Estado federal". Complementa, ainda, sua assertiva colocando que, "[...] do mesmo modo que um Estado federal se distingue de um Estado unitário, uma confederação internacional de Estados se distingue do Estado federal apenas por meio de um grau de descentralização maior".

Quando da análise da implantação do federalismo nos Estados Unidos, considerado o Modelo Clássico de Federalismo, Hamilton, Madison e Jay (1984, p. 383) afirmaram que:

Os poderes delegados ao governo federal pela Constituição proposta são poucos e definidos; os que permanecem com os governos estaduais são numerosos e imprecisos. Aqueles serão exercidos principalmente sobre tópicos externos, tais como guerra, paz, 
negociações e comércio exterior, com o qual o poder de taxação estará mais intimamente ligado. Os poderes reservados aos Estados se estenderão sobre todos os tópicos que, no curso normal da vida do país, dizem respeito às liberdades e bens do povo, à ordem interna $\mathrm{e}$ aos aperfeiçoamentos e progresso do Estado.

No entanto, devido a vários fatores, tal entendimento foi paulatinamente mudando. Schwartz, em análise mais recente sobre o federalismo norte-americano, defende que "[...] o ponto de partida do sistema americano pode [...] ter sido o conceito do federalismo duplo, de acordo com o qual o estado e a Nação eram vistos como iguais". Diz ainda que cada um possui uma área determinada na qual podia atuar. Segundo o mesmo autor, "[...] este conceito foi mantido em seus aspectos essenciais durante mais de um século por uma série de decisões da Corte Suprema que invalidaram tentativas do Governo Federal de invadir o campo reservado aos estados", sendo "[...] o equilíbrio entre o poder estadual e o poder federal [...] alterado drasticamente (somente) durante [...] (o) século (XX)". Aponta, ainda, que "[...] a necessidade do exercício do poder nacional para atender às exigências governamentais dos dias atuais levou ao abandono da noção da igualdade governamental como a pedra angular da estrutura do federalismo americano." (SCHWARTZ, 1984, p. 73). E complementa:

O federalismo, nos Estados Unidos, caracteriza-se agora pelo predomínio da autoridade federal. O sistema social e econômico americano tem estado sujeito cada vez mais à regulamentação e ao controle por Washington. O poder do Governo nacional sobre o comércio é interpretado de modo a sujeitar até mesmo empreendimentos com somente efeito remoto sobre a economia nacional a minuciosas normas federais. $E$, à medida que a autoridade da Nação a este respeito cresceu, a dos estados sofreu correspondente decréscimo, pois a ação estadual, no sistema americano, é barrada quando é validamente exercido o poder federal incompatível com ela. (SCHWARTZ, 1984, p. 74). 
Fazendo uma análise comparativa entre o federalismo norteamericano e o brasileiro, Borges Netto $(1999$, p. 42) diz que a principal diferença "[...] reside no aspecto histórico de o Estado Federal, em terras brasileiras, não ter surgido da manifestação de vontade das antigas províncias, posteriormente transformadas em Estados-membros". O autor, assim como vários estudiosos, entende que "[...] não houve, entre nós, livre consentimento das entidades federadas para a formação da aliança federal, pois a implantação do federalismo se deu da ordem jurídica central (União) para as ordens jurídicas periféricas (Estadosmembros)." (BORGES NETTO, 1999, p. 42).

Nesse sentido, Cavalcanti (1983, p. 122) também argumenta que:

$\mathrm{O}$ ato do governo revolucionário, que autenticou a proclamação da República Federativa, e declarou, que as províncias do Brasil, reunidas pelo laço da federação, ficavam constituindo os "Estados Unidos do Brasil", não os investiu, só por isso, de direitos próprios, irredutíveis, que Ihes dessem o caráter de Estados independentes; e o Congresso Constituinte, que veio, logo depois, e aprovou os intuitos e atos do movimento revolucionário, também não consignou na Constituição federal nenhum poder ou prerrogativa, em favor dos Estados, além do que parecera indispensável para dar-lhe autonomia, com membros da Federação.

A descentralização política é apontada por Borges Netto (1999, p. 46) como o cerne do federalismo ao propor que "[...] a própria razão de ser do Estado Federal reside na característica da descentralização política". Segundo o seu conceito, essa descentralização política significa a "[...] repartição constitucional da capacidade de emissão de normas jurídicas, para que cada esfera de poder possa controlar as condutas dos agentes públicos e dos cidadãos em determinada comunidade jurídica". Considera, ainda, essa característica do Estado Federal como o "ponto central da organização federativa".

Horta (2003, p. 346) nos diz que a Constituição Federal de 1988 apresenta uma "nova repartição de competências", que não apresenta 
"prejuízo dos poderes soberanos e nacionais da União". Segundo o autor, "[...] foram acrescidos (aos poderes da União) [...] expressivas atribuições novas.", e ficou criado o "[...] domínio autônomo da legislação concorrente, abastecido com matérias próprias, e não com matérias deslocadas da competência legislativa da União, [...] para que sejam elas objeto da legislação federal de normas gerais e da legislação suplementar". Ainda argumenta que as legislações estaduais têm autonomia para aperfeiçoar a legislação federal, para que, assim, possa atender às especificidades e exigências locais.

Ramos (2000, p. 189), no entanto, alerta que a autonomia dos Estados-membros é "[...] excessivamente limitada por vários dispositivos constitucionais".

Nesse mesmo sentido, Almeida indica que "[...] em termos técnicos, cabe fazer uma crítica quanto à inclusão, no artigo 22 (da Constituição Federal de 1988), de matérias que serão objeto de normas gerais ou de diretrizes estabelecidas pela União.", como é o caso das "diretrizes e bases da educação nacional" (ALMEIDA, 2000, p. 103). Conforme o autor bem aponta, essa falha técnica apresenta consequências reais, trazendo prejuízo à competência de legislar dos estados (ALMEIDA, 2000, p. 104).

Rodrigues (2002, p. 55-56), por sua vez, afirma que:

Para que se possa efetivar uma adequada leitura da legislação educacional brasileira, no que se refere especificamente ao tema pertinente à definição das diretrizes curriculares, necessário se faz ressaltar três dentre os princípios gerais estabelecidos pela Constituição Federal de 1988, em seu artigo 206: O ensino será ministrado com base nos seguintes princípios: [...] II - liberdade de aprender, ensinar, pesquisar e divulgar o pensamento, a arte e o saber; III - pluralismo de ideias (sic) e de concepções pedagógicas [...]; VII garantia de padrão de qualidade. [...] Em resumo, a ordem constitucional brasileira garante a liberdade e o pluralismo, mas exige a preservação da qualidade. Para garantir que essa qualidade seja mantida, estabelece a necessidade da avaliação, por parte do Poder Público. 
Isso significa que o Poder Público tem de garantir, de um lado, flexibilidade suficiente para que as IESs possam, nas suas propostas pedagógicas, realizar os mandamentos constitucionais e, de outro, que essa flexibilidade possui como limites, também fixados pelo Poder Público, os padrões de qualidade a serem exigidos mediante processos avaliativos oficiais.

Uma possível crise para o federalismo é vista por Cavalcanti, que aponta três causas para isso, o que implicaria na quebra da unidade ou de extinção. O primeiro seria "[...] o desrespeito da Constituição, das leis e atos do poder federal, por parte dos Estados, seja por fatos diretos, seja por omissão voluntária"; o segundo seria o "[...] predomínio de um ou mais Estados sobre os outros, em vista da sua importância política, da sua população, ou da sua força e riqueza"; e o terceiro, "[...] a exorbitância do poder central, procurando absorver as autonomias locais." (CAVALCANTI, 1983, p. 290).

O federalismo atual também é criticado por Pinto Filho, não em função de sua estrutura em si, mas em função do seu mau uso. Segundo ele:

A descentralização, politicamente tão identificada com os momentos democráticos, não tem sido a regra nestes tempos de retorno à democracia. $O$ que mais melindra o federalismo que defendemos não é a sua centralização histórica. É, verdadeiramente, a disparidade dos discursos de nossos governantes que por tanto tempo atacaram o regime anterior como autoritário e centralizador e agora usam das mesmas regras daquele para minar as autonomias estaduais e municipais, mas com uma agravante: utilizam-se das regras e dos discursos democráticos para praticarem aquilo que sempre foi objeto de suas defenestrações. (PINTO FILHO, 2002, p. 211).

Segundo Motter e Gomes, em posfácio do livro de Planck sobre a política educacional no Brasil, em função dos últimos anos (leia-se Governo Fernando Henrique Cardoso), a "[...] estrutura descentralizada 
do sistema educacional brasileiro" pode ser entendida como um "[...] mito [...] em razão da 'recentralização' de funções nas mãos do Ministério da Educação (MEC) promovida pela legislação educacional". Completa dizendo que isso lhe dá "[...] um poder incontrastável na formulação das políticas de educação básica e no controle das redes estaduais e municipais de ensino." e faz isso "[...] através de sistemas nacionais de avaliação, das diretrizes e parâmetros curriculares nacionais, dos critérios de distribuição de verbas federais, etc." (PLANCK, 2001, p. 197-199).

\section{O ESTADO DE BEM-ESTAR SOCIAL BRASILEIRO}

Assim como a ideia de Estado Federal, o conceito de Estado de bem-estar social (ou welfarestate) surgiu nos Estados Unidos, tendo suas primeiras raízes na década de 1930 com o plano new deal, aplicado pelo então presidente do país Franklin Roosevelt, quando houve "[...] um apoio maciço a programas de obras públicas, regulamentação de crédito, controle sob a produção agrícola; regulação das horas de trabalho; salários mínimos; negociação coletiva; sistema abrangente de seguros sociais." (STRECK; MORAIS, 2000, p. 59).

O welfarestate se destaca de forma definitiva, segundo Streck e Morais (2000, p. 68-69), “[...] como consequência geral das políticas definidas a partir das grandes guerras". Na primeira guerra mundial, o Estado se inseriu na produção e distribuição de bens de consumo; já em 1929, por conta da crise financeira, houve interferência estatal na economia; e, em 1940, a atitude interventiva é consolidada com a ideia de que deve haver a proteção de todo o cidadão.

Com a Segunda Guerra Mundial (1939-1945), as práticas intervencionistas do Estado nas questões econômicas e sociais foram ainda mais estimuladas. Dallari (2011, p. 275) explica que isso se deu devido à necessidade estatal de controlar recursos sociais e otimizar da melhor forma a verba pública, haja vista as urgências geradas pela guerra.

Gomes (2006, p. 203) define o Estado de bem-estar social da seguinte forma: 
A definição de welfarestate pode ser compreendida como um conjunto de serviços e benefícios sociais de alcance universal promovidos pelo Estado com a finalidade de garantir uma certa "harmonia" entre o avanço das forças de mercado e uma relativa estabilidade social, suprindo a sociedade de benefícios sociais que significam segurança aos indivíduos para manterem um mínimo de base material e níveis de padrão de vida, que possam enfrentar os efeitos deletérios de uma estrutura de produção capitalista desenvolvida e excludente.

Entende-se o Estado de bem-estar social, segundo Benevides (2011, p. 17), como "[...] o reconhecimento do papel do Estado na busca do bem-estar dos indivíduos, baseando-se nos direitos sociais dos mesmos". A autora completa afirmando que cada país implementou esse sistema de acordo com suas especificidades históricas, haja vista cada nação ter suas próprias características.

Há dois modelos de intervenção social do Estado que são considerados base para todos os outros que vieram a surgir posteriormente: o inglês e o alemão. Na Inglaterra, pode-se perceber uma forte associação entre a centralização do poder, típico dos Estados absolutistas; a dispensa da mão de obra camponesa, devido à mercantilização das terras; e o acolhimento oferecido à população mais pobre. Isso deu origem a um tipo pioneiro de assistencialismo. Já no modelo alemão, nota-se aproximação entre a legislação bismarckiana e o movimento de oposição ao socialismo. Além disso, percebe-se grande distinção entre o assistencialismo e todas as outras formas anteriores de ajuda mútua (FIORI, 1997).

No Brasil, como nos outros países, o surgimento do Estado de bem-estar social teve suas próprias características. Segundo Lobato (2016, p. 89), as políticas sociais implementadas durante a história no Brasil possuíam grande ligação a projetos econômicos e políticos, "[...] deixando a um plano secundário a adoção de estratégias para a melhoria efetiva das condições de vida e criação de padrões mínimos de igualdade social".

Conforme Bonevides (2011, p. 62), os programas de proteção social, nessa época, foram regidos pelo autoritarismo, pois tinha a intenção 
de conduzir questões referentes à "[...] organização dos trabalhadores assalariados dos setores mais modernos da economia, utilizando-se da antecipação de algumas necessidades, de modo a reduzir a legitimidade das lideranças trabalhistas em suas reivindicações".

Lobato (2016, p. 90) diz que, com o decorrer do tempo, o processo de democratização no Brasil, que teve seu ápice com a promulgação da Constituição Federal de 1988, trouxe um novo conceito de cidadania. A autora ainda pontua que a Constituição de 1988 traz um capítulo específico para falar sobre os direitos sociais (saúde, assistência, previdência, educação, dentre outros).

Algumas conquistas trazidas pela nova Constituição são destacadas por Bonevides (2011, p. 65), dentre elas: “[...] a criação do Sistema Unificado de Saúde (SUS), apoiado no direito universal à saúde; a definição de um piso mínimo para os benefícios; a criação do segurodesemprego; e a extensão da previdência rural".

Apesar de reconhecer a promulgação da Constituição como o ápice do processo de democratização brasileiro, Kelsen (1992 apud LOBATO, 2016, p. 90) faz uma crítica ao atual modelo de Estado de bemestar, ao dizer que:

A Constituição representou uma ruptura legal baseada em noções pouco sólidas na estrutura social brasileira, como cidadania, democracia e solidariedade social. Constitucionaliza-se ali um novo pacto social, mas suas bases foram frágeis. A ordem social prevista impunha uma nova forma de Estado em uma sociedade com baixos níveis de organização social, antidemocrática em suas instituições estatais e sociais e profundamente desigual. Do ponto de vista organizacional, a política social apresentava uma potente estrutura de oferta e garantia de bens sociais, mas de baixa cobertura, restrita às parcelas médias e ao mercado formal, burocratizada, permeada por particularismos e com alto grau de corrupção. O modelo constitucional teria que conviver com o passado das políticas sociais, com os projetos governamentais que lhe sucederam e com os valores da sociedade que o adotou. 
Mas não se pode negar que o movimento de redemocratização no Brasil e a promulgação da Constituição da República Federativa do Brasil em 1988 foram fatos históricos que fizeram com que o Estado de bem-estar social fosse implementado no Brasil, garantindo aos cidadãos diversos direitos sociais.

\section{O DIREITO À EDUCAÇÃO COMO UM DIREITO SOCIAL}

Os direitos sociais começaram a ser visados no período pósguerra, junto com o surgimento do Estado de bem-estar social, quando o Estado passou a garantir condições mais dignas de vida à população. No Brasil, a Constituição de 1934 foi a primeira a tratar sobre esses direitos, dando maior ênfase ao direito do trabalho (SALES; PACHÚ, 2015).

$\mathrm{Na}$ Constituição Federal de 1988, os direitos sociais são elencados em seu artigo 6‥ São eles "[...] a educação, a saúde, a alimentação, o trabalho, a moradia, o transporte, o lazer, a segurança, a previdência social, a proteção à maternidade e à infância, a assistência aos desamparados, na forma desta Constituição." (BRASIL, 1988).

Conforme Moraes (2014, p. 203), os "[...] direitos sociais são direitos fundamentais do homem.", e têm como objetivo melhorar a qualidade da vida da população, buscando a igualdade social.

Silva (2014, p. 288-289) ratifica os dizeres de Moraes ao dizer que os direitos sociais são uma extensão dos direitos fundamentais, e "[...] que possibilitam melhores condições de vida aos mais fracos, direitos que tendem a realizar a igualização de situações sociais desiguais". O autor completa afirmando que tais direitos se caracterizam por serem prestações positivas realizadas de forma direta ou indireta pelo Estado e que estão expressas na Constituição Federal.

Ressalta-se que os direitos sociais estão inclusos no Título Il da Constituição Federal. Ou seja, são considerados como direitos fundamentais do cidadão. 
Os Direitos Sociais se constituem direitos fundamentais do homem, inerentes aos indivíduos, configurando-se doutrinariamente como direitos de segunda dimensão. Cabe ressaltar, apenas o reconhecimento da importância de tais direitos não é suficiente, faz-se necessário sua efetivação. Nesse ínterim, as políticas públicas constituem instrumento de viabilização dos direitos básicos da população e enfatiza o caráter ideológico do Direito, busca-se a política de legitimação do poder. A teoria crítica, preconiza a atuação concreta do operador do direito, na concepção do conhecimento não somente como interpretação do mundo, e, sim, transformação. (SALES; PACHÚ, 2015, p. 28).

Dentre os direitos sociais, encontra-se o direito à educação. A primeira vez que a educação é vista internacionalmente como um direito é na Declaração Universal dos Direitos Humanos, assinada na Assembleia Geral da Organização das Nações Unidas em 1948. O preâmbulo da Declaração diz que "[...] cada indivíduo e cada órgão da sociedade tendo sempre em mente esta Declaração." deve se esforçar "[...] por meio do ensino e da educação, por promover o respeito a esses direitos e liberdades." (ONU, 1948).

Em âmbito nacional, o direito à educação está disposto no artigo 6 ㅇ da Constituição Federal. Para além do artigo 60, esse direito social aparece também nos artigos de 205 a 214. Conforme o artigo 205, a educação é um "[...] direito de todos e dever do Estado e da família" e terá incentivo "[...] com a colaboração da sociedade, visando ao pleno desenvolvimento da pessoa, seu preparo para o exercício da cidadania e sua qualificação para o trabalho." (BRASIL, 2018a).

Dessa forma, o Estado necessita de organização e aparelhamento para fornecer a todos e de forma indistinta os serviços de educação, sempre respeitando os princípios constitucionais constantes no artigo 206, da Constituição Federal de 1988, visando cada vez mais à ampliação das possibilidades para que todos os cidadãos tenham acesso ao ensino (SILVA, 2014).

É dever do Estado, conforme artigo 208, inciso I, garantir "[...] educação básica obrigatória e gratuita dos 4 (quatro) aos 17 (dezessete) 
anos de idade, assegurada inclusive sua oferta gratuita para todos os que a ela não tiveram acesso na idade própria." (BRASIL, 1988). Segundo Silva (2014, p. 317), essa garantia se traduz num direito público subjetivo e "[...] equivale reconhecer que é direito plenamente eficaz e de aplicabilidade imediata, isto é, direito exigível judicialmente, se não for prestado espontaneamente".

$\mathrm{O}$ artigo 22, inciso XXIV, determina é que de competência privativa da União legislar sobre as diretrizes e bases da educação (BRASIL, 1988). Porém, o dever com a educação é de todos os entes federativos. Assim como o dever com a educação, o regime de colaboração também é mútuo e recíproco:

\begin{abstract}
A Constituição Federal determina, com caráter de obrigatoriedade, que a União aplique, anualmente, nunca menos de $18 \%$, e os Estados, o Distrito Federal e os Municípios 25\%, no mínimo, da receita resultante de impostos, compreendida a proveniente de transferências, na manutenção e no desenvolvimento do ensino, excluindo-se a parcela da arrecadação de impostos transferida pela União aos Estados, ao Distrito Federal e aos Municípios, ou pelos Estados aos respectivos Municípios. A distribuição dos recursos públicos assegurará, nos termos da EC n. 59/09, prioridade ao atendimento das necessidades do ensino obrigatório, no que se refere a universalização, garantia de padrão de qualidade e equidade, nos termos do plano nacional de educação. (MORAES, 2014, p. 857).
\end{abstract}

A Constituição Federal de 1988 também prevê, como fonte adicional de financiamento à educação básica pública, a contribuição social do salário-educação, conforme dita o parágrafo 5o do artigo 212 (BRASIL, 1988).

Para além dos investimentos em educação, deve-se atentar às políticas públicas educacionais, que são formas de fazer com que o disposto na Constituição Federal atinja seu objetivo. 


\section{POLÍTICAS PÚBLICAS EDUCACIONAIS COMO FORMA DE APLICAÇÃO DOS DISPOSITIVOS CONSTITUCIONAIS}

O termo "política pública" se refere a questões coletivas e integra a esfera pública, o que não significa dizer que é necessariamente algo estatal, pois, apesar de o Estado estar voltado totalmente para a esfera pública, há organizações sociais que também possuem finalidades públicas expressas, mas que não são estatais (SCHMIDT, 2008).

Políticas públicas, conforme Schmidt (2008, p. 2.311), nada mais são do que o resultado de uma política institucional, e "[...] se materializam em diretrizes, programas, projetos e atividades que visam a resolver problemas e demandas da sociedade". Dentro das diversas políticas públicas desenvolvidas nacionalmente, há as políticas educacionais e, dentre essas, há as que avaliam os índices da educação básica no Brasil.

A avaliação da qualidade educação pública e privada é garantida pela Constituição de 1988 em seus artigos 206, inciso VII, e 209. O artigo 206, inciso VII, traz que um dos princípios do ensino no Brasil é a "[...] garantia de padrão de qualidade", enquanto que o artigo 209 diz que a iniciativa privada é livre para implementar o ensino, desde que autorize o Poder Público realizar avaliação de qualidade (BRASIL, 1988).

Com isso, o MEC lançou, em abril de 2007, o Plano do Desenvolvimento da Educação (PDE), plano esse que foi normatizado pelo Decreto Presidencial n. 6.094, e explana sobre o "Plano de Metas Compromisso Todos pela Educação". Essa política pública possui como objetivo aprimorar a qualidade da educação básica, prevendo ações e políticas para os diversos níveis de ensino em todos os entes federativos (OLIVEIRA, 2014).

Naquele mesmo ano e em decorrência do PDE, foi criado o Índice de Desenvolvimento da Educação Básica (IDEB),

[...] que se propõe a medir a qualidade da educação brasileira nos âmbitos nacional, estadual, municipal e em cada escola. O IDEB é um indicador de qualidade 
educacional que agrega os resultados de desempenho dos estudantes brasileiros (obtidos pela Prova Brasil) e rendimento escolar - taxa média de aprovação na etapa de ensino (obtidos pelo Censo Escolar). É, portanto, resultado do produto entre a média padronizada da Prova Brasil (da escola/ rede de ensino/município), ajustada para expressar valores entre 0 e 10 , e o número de anos que os alunos levam para concluir uma série. (OLIVEIRA, 2014, p. 412).

O IDEB foi formulado pelo Instituto Nacional de Estudos e Pesquisas Educacionais Anísio Teixeira (Inep) e seu objetivo é medir a qualidade do ensino e criar metas para melhorá-lo. Assim, o IDEB opera "[...] como um indicador nacional que possibilita o monitoramento da qualidade da Educação pela população por meio de dados concretos, com o qual a sociedade pode se mobilizar em busca de melhorias." (BRASIL, 2016).

No portal oficial do Inep podem-se analisar os dados do IDEB, que são colhidos a cada dois anos, sempre nos anos ímpares. No ano de 2005, foram traçadas metas bienais para que se atinja, até o ano de 2021, o objetivo educacional da Organização para a Cooperação e Desenvolvimento Econômico (OCDE), que é a nota 6,0 (INEP, 2018a).

A tabela a seguir colacionada traz os dados do IDEB de cada um dos três estados integrantes da Região Sul do Brasil, quais sejam: Paraná, Rio Grande do Sul e Santa Catarina, a partir do ano de 2005 (os índices em destaque foram os que alcançaram a meta estabelecida para o período de avaliação).

Tabela 1 - IDEB obtido nos estados da Região Sul do Brasil

\section{Estado do Paraná}

4a série/5ㅇa ano

\begin{tabular}{|c|c|c|c|c|c|c|c|c|c|c|c|c|c|c|}
\hline & \multicolumn{6}{|c|}{ Ideb Observado } & \multicolumn{8}{|c|}{ Metas Projetadas } \\
\hline $\begin{array}{c}\text { Estado } \\
\neq\end{array}$ & $\begin{array}{c}005 \\
\Leftrightarrow\end{array}$ & $\begin{array}{c}007 \\
*\end{array}$ & $\begin{array}{c}009 \\
*\end{array}$ & $\begin{array}{c}011 \\
*\end{array}$ & $\begin{array}{c}013 \\
*\end{array}$ & $\begin{array}{c}015 \\
*\end{array}$ & $\begin{array}{c}007 \\
\neq\end{array}$ & $\begin{array}{c}009 \\
*\end{array}$ & $\begin{array}{c}011 \\
\Leftrightarrow\end{array}$ & $\begin{array}{c}013 \\
*\end{array}$ & $\begin{array}{c}015 \\
*\end{array}$ & $\begin{array}{c}017 \\
\Leftrightarrow\end{array}$ & $\begin{array}{c}019 \\
*\end{array}$ & $\begin{array}{c}021 \\
*\end{array}$ \\
\hline Paraná & 4.6 & 5.0 & 5.4 & 5.6 & 5.9 & 6.2 & 4.7 & 5.0 & 5.4 & 5.6 & 5.9 & 6.2 & 6.4 & 6.6 \\
\hline
\end{tabular}


8a série/9ㅇano

\begin{tabular}{|c|c|c|c|c|c|c|c|c|c|c|c|c|c|c|}
\hline & \multicolumn{6}{|c|}{ Ideb Observado } & \multicolumn{8}{|c|}{ Metas Projetadas } \\
\hline $\begin{array}{c}\text { Estado } \\
\star\end{array}$ & $\begin{array}{c}005 \\
*\end{array}$ & $\begin{array}{c}007 \\
*\end{array}$ & $\begin{array}{l}009 \\
*\end{array}$ & $\begin{array}{c}011 \\
*\end{array}$ & $\begin{array}{c}013 \\
*\end{array}$ & $\begin{array}{c}015 \\
*\end{array}$ & $\begin{array}{c}007 \\
*\end{array}$ & 009 & $\begin{array}{c}011 \\
*\end{array}$ & $\begin{array}{c}013 \\
*\end{array}$ & $\begin{array}{c}015 \\
\star\end{array}$ & 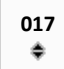 & $\begin{array}{c}019 \\
*\end{array}$ & $\begin{array}{c}021 \\
*\end{array}$ \\
\hline Paraná & 4.6 & 5.0 & 5.4 & 5.6 & 5.9 & 6.2 & 4.7 & 5.0 & 5.4 & 5.6 & 5.9 & 6.2 & 6.4 & 6.6 \\
\hline
\end{tabular}

\section{3a série/3ㅇano do ensino médio}

\begin{tabular}{|c|c|c|c|c|c|c|c|c|c|c|c|c|c|c|}
\hline & \multicolumn{6}{|c|}{ Ideb Observado } & \multicolumn{8}{|c|}{ Metas Projetadas } \\
\hline $\begin{array}{c}\text { Estado } \\
\Rightarrow\end{array}$ & $\begin{array}{c}005 \\
*\end{array}$ & $\begin{array}{c}007 \\
*\end{array}$ & $\begin{array}{c}009 \\
*\end{array}$ & $\begin{array}{c}011 \\
*\end{array}$ & $\begin{array}{c}013 \\
*\end{array}$ & $\begin{array}{c}015 \\
*\end{array}$ & $\begin{array}{c}007 \\
\Leftrightarrow\end{array}$ & $\begin{array}{c}009 \\
\Rightarrow\end{array}$ & $\begin{array}{c}011 \\
\Leftrightarrow\end{array}$ & $\begin{array}{c}013 \\
\Leftrightarrow\end{array}$ & $\begin{array}{c}015 \\
\Rightarrow\end{array}$ & $\begin{array}{c}017 \\
\Leftrightarrow\end{array}$ & $\begin{array}{c}019 \\
*\end{array}$ & $\begin{array}{c}021 \\
\Rightarrow\end{array}$ \\
\hline Paraná & 3.6 & 4.0 & 4.2 & 4.0 & 3.8 & 3.9 & 3.6 & 3.7 & 3.9 & 4.2 & 4.5 & 5.0 & 5.2 & 5.4 \\
\hline
\end{tabular}

\section{Estado do Rio Grande do Sul}

4aㅗ série/5ㅇa ano

\begin{tabular}{|c|c|c|c|c|c|c|c|c|c|c|c|c|c|c|}
\hline & \multicolumn{6}{|c|}{ Ideb Observado } & \multicolumn{8}{|c|}{ Metas Projetadas } \\
\hline $\begin{array}{c}\text { Estado } \\
\neq\end{array}$ & $\begin{array}{c}005 \\
*\end{array}$ & $\begin{array}{c}007 \\
\leftarrow\end{array}$ & $\begin{array}{c}009 \\
\Leftrightarrow\end{array}$ & $\begin{array}{c}011 \\
*\end{array}$ & $\begin{array}{c}013 \\
*\end{array}$ & $\begin{array}{c}015 \\
\rightleftharpoons\end{array}$ & $\begin{array}{c}007 \\
\Leftrightarrow\end{array}$ & $\begin{array}{c}009 \\
\Leftrightarrow\end{array}$ & $\begin{array}{c}011 \\
\Leftrightarrow\end{array}$ & $\begin{array}{c}013 \\
*\end{array}$ & $\begin{array}{c}015 \\
*\end{array}$ & $\begin{array}{c}017 \\
*\end{array}$ & $\begin{array}{c}019 \\
\approx\end{array}$ & $\begin{array}{c}021 \\
\Leftrightarrow\end{array}$ \\
\hline $\begin{array}{l}\text { Rio } \\
\text { Grande } \\
\text { do Sul }\end{array}$ & 4.3 & 4.6 & 4.9 & 5.1 & 5.6 & 5.7 & 4.3 & 4.7 & 5.1 & 5.3 & 5.6 & 5.9 & 6.1 & 6.4 \\
\hline
\end{tabular}

8aㅗ série/9a ano

\begin{tabular}{|c|c|c|c|c|c|c|c|c|c|c|c|c|c|c|}
\hline & \multicolumn{6}{|c|}{ Ideb Observado } & \multicolumn{8}{|c|}{ Metas Projetadas } \\
\hline $\begin{array}{c}\text { Estado } \\
*\end{array}$ & $\begin{array}{c}005 \\
*\end{array}$ & $\begin{array}{c}007 \\
*\end{array}$ & $\begin{array}{c}009 \\
*\end{array}$ & $\begin{array}{c}011 \\
*\end{array}$ & $\begin{array}{c}013 \\
*\end{array}$ & $\begin{array}{c}015 \\
\neq\end{array}$ & $\begin{array}{c}007 \\
+\end{array}$ & $\begin{array}{c}009 \\
*\end{array}$ & $\begin{array}{c}011 \\
\neq\end{array}$ & $\begin{array}{c}013 \\
*\end{array}$ & $\begin{array}{c}015 \\
*\end{array}$ & $\begin{array}{c}017 \\
*\end{array}$ & $\begin{array}{c}019 \\
\neq\end{array}$ & $\begin{array}{c}021 \\
\neq\end{array}$ \\
\hline $\begin{array}{l}\text { Rio } \\
\text { Grande } \\
\text { do Sul }\end{array}$ & 3.8 & 3.9 & 4.1 & 4.1 & 4.2 & 4.3 & 3.9 & 4.0 & 4.3 & 4.7 & 5.1 & 5.3 & 5.6 & 5.8 \\
\hline
\end{tabular}

\section{3a série/3ㅇano do ensino médio}

\begin{tabular}{|c|c|c|c|c|c|c|c|c|c|c|c|c|c|c|}
\hline & \multicolumn{6}{|c|}{ Ideb Observado } & \multicolumn{8}{|c|}{ Metas Projetadas } \\
\hline $\begin{array}{c}\text { Estado } \\
\neq\end{array}$ & $\begin{array}{c}005 \\
*\end{array}$ & $\begin{array}{c}007 \\
*\end{array}$ & $\begin{array}{c}009 \\
*\end{array}$ & $\begin{array}{c}011 \\
*\end{array}$ & $\begin{array}{c}013 \\
*\end{array}$ & $\begin{array}{c}015 \\
*\end{array}$ & $\begin{array}{c}007 \\
*\end{array}$ & $\begin{array}{c}009 \\
*\end{array}$ & $\begin{array}{c}011 \\
*\end{array}$ & $\begin{array}{c}013 \\
*\end{array}$ & $\begin{array}{c}015 \\
*\end{array}$ & $\begin{array}{c}017 \\
*\end{array}$ & $\begin{array}{c}019 \\
*\end{array}$ & $\begin{array}{r}021 \\
*\end{array}$ \\
\hline $\begin{array}{l}\text { Rio } \\
\text { Grande } \\
\text { do Sul }\end{array}$ & 3.7 & 3.7 & 3.9 & 3.7 & 3.9 & 3.6 & 3.8 & 3.9 & 4.0 & 4.3 & 4.6 & 5.1 & 5.3 & 5.5 \\
\hline
\end{tabular}




\section{Estado do Santa Catarina}

4a série/5으 ano

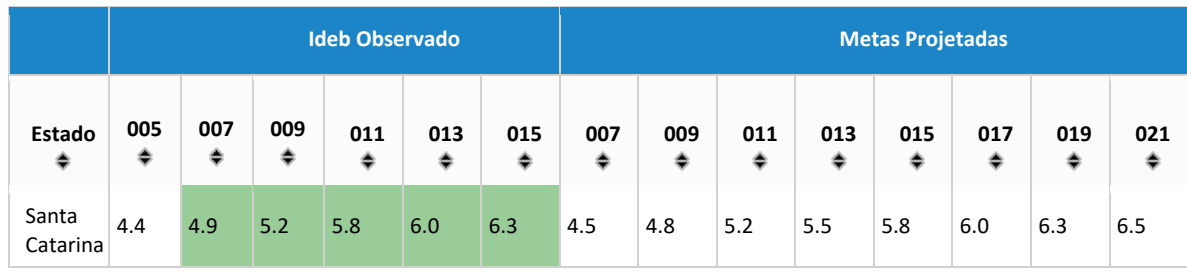

8a série/9ㅇano

\begin{tabular}{|c|c|c|c|c|c|c|c|c|c|c|c|c|c|c|}
\hline & \multicolumn{6}{|c|}{ Ideb Observado } & \multicolumn{8}{|c|}{ Metas Projetadas } \\
\hline $\begin{array}{c}\text { Estado } \\
\Leftrightarrow\end{array}$ & $\begin{array}{c}005 \\
*\end{array}$ & $\begin{array}{c}007 \\
*\end{array}$ & $\begin{array}{c}009 \\
*\end{array}$ & $\begin{array}{c}011 \\
\Leftrightarrow\end{array}$ & $\begin{array}{c}013 \\
*\end{array}$ & $\begin{array}{c}015 \\
\Leftrightarrow\end{array}$ & $\begin{array}{c}007 \\
*\end{array}$ & $\begin{array}{c}009 \\
\approx\end{array}$ & $\begin{array}{c}011 \\
*\end{array}$ & $\begin{array}{c}013 \\
*\end{array}$ & $\begin{array}{c}015 \\
*\end{array}$ & $\begin{array}{c}017 \\
=\end{array}$ & $\begin{array}{c}019 \\
*\end{array}$ & $\begin{array}{c}021 \\
*\end{array}$ \\
\hline $\begin{array}{l}\text { Santa } \\
\text { Catarina }\end{array}$ & 4.3 & 4.3 & 4.5 & 4.9 & 4.5 & 5.1 & 4.3 & 4.5 & 4.7 & 5.1 & 5.5 & 5.7 & 6.0 & 6.2 \\
\hline
\end{tabular}

3a série/3ㅇa ano ensino médio

\begin{tabular}{|c|c|c|c|c|c|c|c|c|c|c|c|c|c|c|}
\hline & \multicolumn{6}{|c|}{ Ideb Observado } & \multicolumn{8}{|c|}{ Metas Projetadas } \\
\hline $\begin{array}{c}\text { Estado } \\
*\end{array}$ & $\begin{array}{c}005 \\
*\end{array}$ & $\begin{array}{c}007 \\
*\end{array}$ & $\begin{array}{c}009 \\
*\end{array}$ & $\begin{array}{c}011 \\
*\end{array}$ & $\begin{array}{c}013 \\
*\end{array}$ & $\begin{array}{c}015 \\
*\end{array}$ & $\begin{array}{c}007 \\
*\end{array}$ & $\begin{array}{c}009 \\
*\end{array}$ & $\begin{array}{c}011 \\
*\end{array}$ & $\begin{array}{c}013 \\
*\end{array}$ & $\begin{array}{c}015 \\
*\end{array}$ & $\begin{array}{c}017 \\
*\end{array}$ & $\begin{array}{c}019 \\
*\end{array}$ & $\begin{array}{c}021 \\
*\end{array}$ \\
\hline $\begin{array}{l}\text { Santa } \\
\text { Catarina }\end{array}$ & 3.8 & 4.0 & 4.1 & 4.3 & 4.0 & 3.8 & 3.8 & 3.9 & 4.1 & 4.4 & 4.7 & 5.2 & 5.4 & 5.6 \\
\hline
\end{tabular}

Fonte: INEP (2018b)

Analisando-se os índices disponibilizados pelo IDEB, verificase que cada estado da Região Sul possui metas diferentes a serem alcançadas, conforme a realidade de cada região. Assim, um exemplo que se pode observar é que, para os alunos de 4a série/50 ano, a meta para o estado do Paraná em 2015 era 5,9, para o Rio Grande do Sul era 5,6 e, para Santa Catarina, 5,8, sendo que todas as metas para o referido ano foram atingidas.

Extrai-se da análise dos dados que, em relação aos primeiros anos do ensino fundamental, o estado do Paraná possui as metas educacionais mais elevadas, seguido por Santa Catarina. O estado do Rio Grande do Sul, 
por sua vez, possui as metas do IDEB mais baixas em relação aos outros dois estados da Região Sul do Brasil.

A média dos índices reais do IDEB para cada período apurado refletiu o esperado das metas: o IDEB do estado do Paraná obteve as maiores notas, seguido pelo estado de Santa Catarina e, por fim, o Rio Grande do Sul.

Para as últimas fases do ensino fundamental, há mudança de situação. Nesse cenário, Santa Catarina surge como o estado com as metas mais elevadas, seguido pelo Rio Grande do Sul e, mais abaixo, Paraná. Para o ensino médio a situação não se altera.

Porém, ao apurar o IDEB real de cada estado para essas fases de ensino (últimas fases do ensino fundamental e ensino médio), vê-se que o estado do Paraná supera os índices obtidos pelo Rio Grande do Sul. Enquanto isso, Santa Catarina permanece em destaque como sendo o estado com o maior IDEB da Região Sul do Brasil.

Ainda há de se atentar ao fato de que nenhum dos três estados atingiu as metas para os últimos anos do ensino fundamental e ensino médio nos últimos dois biênios analisados (2013 e 2015). Todos ficaram aquém do objetivo estipulado, situação que deve gerar alerta aos gestores públicos para que seja averiguada a real situação da qualidade da educação em cada região.

Apesar de ser um índice oficial do Governo Federal, o IDEB é cercado de críticas e questionamentos relacionados ao método utilizado para a avaliação da educação. Freitas (2007, p. 971-972) diz que:

É importante saber se a aprendizagem em uma escola de periferia é baixa ou alta. Mas fazer do resultado o ponto de partida para um processo de responsabilização da escola via prefeituras leva-nos a explicar a diferença baseados na ótica meritocrática liberal: mérito do diretor que é bem organizado; mérito das crianças que são esforçadas; mérito dos professores que são aplicados; mérito do prefeito que deve ser reeleito etc. Mas e as condições de vida dos alunos e professores? $\mathrm{E}$ as políticas governamentais inadequadas? $\mathrm{E}$ o que restou de um serviço público do qual as elites, para se 
elegerem, fizeram de cabide de emprego generalizado, enquanto puderam, sem regras para contratação ou demissão? 0 que dizer da permanente remoção de professores e especialistas a qualquer tempo, pulando de escola em escola? O que dizer dos professores horistas que se dividem entre várias escolas? 0 que dizer dos alunos que habitam as crescentes favelas sem condições mínimas de sobrevivência e muito menos para criar um ambiente propício ao estudo? Sem falar do número de alunos em sala de aula.

E arremata: “[...] escolher apenas uma variável, desempenho do aluno, para analisar a educação básica brasileira, como o IDEB faz, é certamente temerário em face deste complexo de variáveis." (FREITAS, 2007, p. 972).

Em contraponto, Machado e Alavarse (2014, p. 422) pontuam que, apesar de o IDEB trazer uma ideia de qualidade baseada em números, sem incluir outros fatores de avaliação e não contemplar pontos importantes do processo pedagógico, este índice possui outros aspectos positivos. Um desses aspectos é que o IDEB tem a capacidade de facilitar a análise da realidade da educação brasileira, mesmo não fazendo isso de uma forma ampla e completa. Além disso, incentiva a melhora desempenho escolar, gerando, em tese, mais qualidade na educação.

Assim, vê-se que possuir índices educacionais para avaliar a educação brasileira é necessário, porém, a discussão acerca do método de avaliação se mostra fundamental para que se tenham índices confiáveis de análise para que, dessa forma, sejam pensadas políticas públicas efetivas para a melhora na educação.

\section{CONSIDERAÇÕES FINAIS}

A conceituação de Estado não é unânime entre a doutrina. Para alguns autores, definir seu conceito se torna difícil pelo fato de que há uma grande variedade de objetos que o vocábulo abrange. O termo é comumente vinculado à sociedade. 
O Estado de bem-estar social surge no período pós-guerra como uma forma de garantir um mínimo de renda, saúde, educação e habitação para todos os cidadãos. Apesar de constituições anteriores versarem algo sobre esses direitos sociais, foi apenas na Constituição Federal de 1988 que esses direitos foram consolidados como direitos fundamentais do cidadão.

A educação aparece na Carta Magna no artigo 6ㅇ, que versa sobre os direitos sociais, e também nos artigos 205 e seguintes. Para assegurar a implementação desses direitos, surgem as políticas públicas educacionais, que dão voz à Constituição e visam à melhoria da qualidade da educação no Brasil.

Para medir os índices educacionais brasileiros, há os indicadores do IDEB, criado em 2007. Analisando os resultados, percebe-se que os estados da Região Sul brasileira possuem especificidades próprias, fato que faz com que as metas educacionais sejam diversas para cada estado. Santa Catarina, de modo geral, destaca-se dentre os outros dois estados da região, porém, vê-se que os três estados estão com os resultados do IDEB aquém da meta estipulada para os últimos dois biênios analisados. Há críticas relacionadas ao IDEB, pois o índice não retrata a real qualidade da educação brasileira, haja vista não levar em consideração uma série de variáveis.

\section{REFERÊNCIAS}

ALMEIDA, F. D. M. Competências na Constituição de 1988. 2. ed. São Paulo: Atlas, 2000.

BENEVIDES, C. do V. Um estado de bem-estar social no Brasil? 2011. $97 \mathrm{f}$. Dissertação (Mestrado em Economia) - Programa de Pós-Graduação em Economia. Universidade Federal Fluminense, Rio de Janeiro, 2011.

BOBBIO, N. Dicionário de política. 5. ed. Brasília, DF: UnB, 2004.

BOBBIO, N. Estado, governo, sociedade: para uma teoria geral da política. 9. ed. Rio de Janeiro: Paz e Terra, 2001. 
BORGES NETTO, A. L. Competências legislativas dos Estados-membros. São Paulo: Revista dos Tribunais, 1999.

BRASIL. Costituição 1988. Constituição da República Federativa do Brasil de 1988. Brasília, DF, 1988. Disponível em: http://www.planalto.gov.br/ccivil_03/constituicao/constituicaocompilado.htm. Acesso em: 9 abr. 2018.

BRASIL. Ministério da Educação e Cultura (MEC). Índice de Desenvolvimento da Educação Básica (IDEP) - Apresentação. 2016. Disponível em: http://portal.mec.gov.br/secretaria-de-educacao-basica/programas-e-acoes?id=180. Acesso em: 17 abr. 2018.

CAVALCANTI, A. Regime Federativo e a República Brasileira. Brasília, DF: UnB, 1983.

DALLARI, D. de A. Elementos de Teoria Geral do Estado. 30. ed. São Paulo: Saraiva, 2011.

FIORI, J. L. Estado de Bem-Estar Social: Padrões e Crises. Physis: Revista de Saúde Coletiva, Rio de Janeiro, v. 2, n. 7, p. 129-147, nov. 1997.

FREITAS, L. C. Eliminação adiada: o caso das classes populares no interior da escola e a ocultação da (má) qualidade do ensino. Educação \& Sociedade, Campinas, v. 28, n. 100, p. 965-987, 2007.

GOMES, F. G. Conflito social e welfarestate: estado e desenvolvimento social no Brasil. Revista de Administração Pública, Rio de Janeiro, v. 40, n. 2, p. 201-234, mar./abr. 2006.

HAMILTON, A.; MADISON, J.; JAY, J. O federalista. Brasília, DF: UnB, 1984.

HORTA, R. M. Direito constitucional. 4. ed. rev. e atual. Belo Horizonte: Del Rey, 2003.

INSTITUTO NACIONAL DE ESTUDOS E PESQUISAS EDUCACIONAIS ANÍSIO TEIXEIRA (Inep). $\mathbf{O}$ que são as metas de qualidade educacional? 2018a. Disponível em:

http://portal.inep.gov.br/metas-educacionais. Acesso em: 27 abr. 2018. 
INSTITUTO NACIONAL DE ESTUDOS E PESQUISAS EDUCACIONAIS ANÍSIO TEIXEIRA (Inep). Índice de Desenvolvimento da Educação Básica (IDEB): resultados e metas. 2018b. Disponível em:

http://ideb.inep.gov.br/resultado/home.seam?cid=1698780. Acesso em: 3 jul. 2018.

KELSEN, H. Teoria geral do direito e do Estado. 2. ed. São Paulo: Martins Fontes, 1992.

LOBATO, L. de V. C. Políticas sociais e modelos de bem-estar social: fragilidades do caso brasileiro. Saúde em Debate, Rio de Janeiro, v. 40, p. 87-97, dez. 2016.

MACHADO, C.; ALAVARSE, O. M. Qualidade das escolas: tensões e potencialidades das avaliações externas. Educação \& Realidade, Porto Alegre, v. 39, n. 2, p. 413-436, abr./jun. 2014.

MORAES, A. de. Direito constitucional. 30. ed. rev. e atual. São Paulo: Atlas, 2014.

OLIVEIRA, A. G. de. Políticas educacionais e a qualidade da Educação nos municípios fluminenses: alguns recortes. Ensaio: avaliação e Políticas Públicas em Educação, Rio de Janeiro, v. 22, p. 411-442, abr./jun. 2014.

ORGANIZAÇÃO DAS NAÇÕES UNIDAS (ONU). Declaração Universal dos Direitos Humanos. 1948. Disponível em: http://www.onu.org.br/img/2014/09/DUDH.pdf. Acesso em: 11 abr. 2018.

PINTO FILHO, F. B. M. A intervenção federal e o federalismo brasileiro. Rio de Janeiro: Forense, 2002.

PLANCK, D. N. Política educacional no Brasil: caminhos para a salvação pública. Porto Alegre: Artmed Editora, 2001.

RAMOS, D. T. O federalismo assimétrico. Rio de Janeiro: Forense, 2000.

RODRIGUES, H. W.; JUNQUEIRA, E. B. Ensino do direito no Brasil: diretrizes curriculares e avaliação das condições de ensino. Florianópolis: Fundação Boiteux, 2002. 
SALES, J. M. A. de; PACHÚ, C. O. Direitos sociais e as políticas públicas como mecanismo de efetivação. Direitos Sociais: 0 art. 60 da Constituição Federal e sua efetividade, Campina Grande, 2015. p. 27-46.

SCHMIDT, J. P. Para entender as políticas públicas: aspectos conceituais e metodológicos. Direitos Sociais e Políticas Públicas: desafios contemporâneos, Santa Cruz do Sul, 2008. p. 2.307-2.333.

SCHWARTZ, B. O federalismo norte-americano atual: uma visão contemporânea. Rio de Janeiro: Forense Universitária. 1984.

SILVA, J. A. da. Curso de direito constitucional positivo. 37. ed. rev. e atual. São Paulo: Malheiros Editores, 2014.

STRECK, L. L.; MORAIS, J. L. B. de. Ciência política e teoria geral do Estado. Porto Alegre: Livraria do Advogado, 2000.

WRIGHT, B. F. Introdução e notas. In: HAMILTON, A.; MADISON, J.; JAY, J. O federalista. Brasília, DF: UnB, 1984. 